\title{
Long-term effects of empagliflozin on excitation-contraction-coupling in human induced pluripotent stem cell cardiomyocytes
}

\author{
Steffen Pabel ${ }^{1}$ • Florian Reetz $^{1} \cdot$ Nataliya Dybkova $^{2} \cdot$ Orr Shomroni $^{3} \cdot$ Gabriela Salinas $^{3} \cdot$ Julian Mustroph $^{1}$. \\ Karin P. Hammer ${ }^{1}$. Gerd Hasenfuss ${ }^{2} \cdot$ Nazha Hamdani $^{4}$ - Lars S. Maier ${ }^{1} \cdot$ Katrin Streckfuss-Bömeke $^{2}$. \\ Samuel Sossalla ${ }^{1,2}$ (1)
}

Received: 13 May 2020 / Revised: 11 September 2020 / Accepted: 1 October 2020 / Published online: 9 October 2020

(C) The Author(s) 2020

\begin{abstract}
The SGLT2 inhibitor empagliflozin improved cardiovascular outcomes in patients with diabetes. As the cardiac mechanisms remain elusive, we investigated the long-term effects (up to 2 months) of empagliflozin on excitation-contraction (EC)-coupling in human cardiomyocytes derived from induced pluripotent stem cells (iPSC-CM) in a blinded manner. IPSC from 3 donors, differentiated into pure iPSC-CM (4 differentiations), were treated with a clinically relevant concentration of empagliflozin $(0.5 \mu \mathrm{mol} / \mathrm{l})$ or vehicle control. Treatment, data acquisition, and analysis were conducted externally blinded. Epifluorescence microscopy measurements in iPSC-CM showed that empagliflozin has neutral effects on $\mathrm{Ca}^{2+}$ transient amplitude, diastolic $\mathrm{Ca}^{2+}$ levels, $\mathrm{Ca}^{2+}$ transient kinetics, or sarcoplasmic $\mathrm{Ca}^{2+}$ load after 2 weeks or 8 weeks of treatment. Confocal microscopy determining possible effects on proarrhythmogenic diastolic $\mathrm{Ca}^{2+}$ release events showed that in iPSC-CM, $\mathrm{Ca}^{2+}$ spark frequency and leak was not altered after chronic treatment with empagliflozin. Finally, in patch-clamp experiments, empagliflozin did not change action potential duration, amplitude, or resting membrane potential compared with vehicle control after long-term treatment. Next-generation RNA sequencing (NGS) and mapped transcriptome profiles of iPSC-CMs untreated and treated with empagliflozin for 8 weeks showed no differentially expressed EC-coupling genes. In line with NGS data, Western blots indicate that empagliflozin has negligible effects on key EC-coupling proteins. In this blinded study, direct treatment of iPSC-CM with empagliflozin for a clinically relevant duration of 2 months did not influence cardiomyocyte EC-coupling and electrophysiology. Therefore, it is likely that other mechanisms independent of cardiomyocyte EC-coupling are responsible for the beneficial treatment effect of empagliflozin.
\end{abstract}

\section{Key messages}

- This blinded study investigated the clinically relevant long-term effects (up to 2 months) of empagliflozin on cardiomyocyte excitation-contraction (EC)-coupling.

- Human cardiomyocytes derived from induced pluripotent stem cells (iPSC-CM) were used to study a human model including a high repetition number of experiments.

- Empagliflozin has neutral effects on cardiomyocyte $\mathrm{Ca}^{2+}$ transients, sarcoplasmic $\mathrm{Ca}^{2+}$ load, and diastolic sarcoplasmic $\mathrm{Ca}^{2+}$ leak.

- In patch-clamp experiments, empagliflozin did not change the action potential.

- Next-generation RNA sequencing, mapped transcriptome profiles, and Western blots of iPSC-CM untreated and treated with empagliflozin showed no differentially expressed EC-coupling candidates.

Keywords Empagliflozin $\cdot$ EC-coupling $\cdot$ Electrophysiology $\cdot$ iPSC-CM

Katrin Streckfuss-Bömeke and Samuel Sossalla contributed equally to this work.

Katrin Streckfuss-Bömeke

katrin.streckfuss@med.uni-goettingen.de

Samuel Sossalla

samuel.sossalla@ukr.de

Extended author information available on the last page of the article

\section{Introduction}

The antidiabetic drug empagliflozin, which inhibits the sodium-dependent glucose cotransporter 2 (SGLT2) in the kidney, has been shown to reduce cardiovascular mortality, all-cause mortality, and hospitalization rates for heart failure (HF) in patients at high cardiovascular risk and type 2 diabetes 
[1]. These beneficial effects have been also confirmed for other SGLT2 inhibitors [2, 3] and, importantly, also in a diabetes-independent manner in patients with HF [4]. Moreover, recent clinical data indicate that this improved cardiovascular outcome might not be dependent on modulation of cardiovascular risk factors as the effects occur already after a few months [5]. Therefore, the question arises whether empagliflozin has direct cardiac effects. Despite a growing number of studies investigating the cardiovascular effects of empagliflozin, the underlying mechanisms are still under debate and remain controversial. Importantly, direct myocardial effects of empagliflozin on cardiac metabolism [6], contractility $[7,8]$, and cardiomyocyte $\mathrm{Ca}^{2+}$ and $\mathrm{Na}^{+}$homeostasis [9, 10] have been proposed. One potential mechanisms might be an inhibitory effect of empagliflozin on the $\mathrm{Na}^{+} / \mathrm{H}^{+}$exchanger (NHE) causing a reduction in myocardial cytoplasmic $\mathrm{Na}^{+}$ and $\mathrm{Ca}^{2+}$ and increased mitochondrial $\mathrm{Ca}^{2+}[10,11]$. As $\mathrm{Ca}^{2+}$ cycling fundamentally determines cardiac excitationcontraction (EC)-coupling and thereby cardiac function, changes in $\mathrm{Ca}^{2+}$ homeostasis are associated with pathological cardiac remodeling and HF [12]. Therefore, the evaluation whether empagliflozin may affect cardiomyocyte ECcoupling is of importance to understand its potential cardiac effects and for further translational investigation. However, the role of empagliflozin for cardiomyocyte EC-coupling is not fully elucidated, and previous reports are limited by small n-numbers. As the systemic effects of empagliflozin may indirectly affect the myocardium, the investigation of the direct cardiac effects of empagliflozin is thus only possible in in vitro models. However, isolated adult cardiomyocytes $(\mathrm{CM})$, as investigated previously $[7,9,10]$, are not suitable for chronic culture and treatment protocols according to the clinical setting, where the beneficial effects of empagliflozin became apparent after $\sim 2$ months of treatment [1].

The aim of this study was to fundamentally investigate the clinically relevant direct long-term effects of empagliflozin on human cardiomyocyte EC-coupling and electrophysiology in a standardized and blinded manner by using human-induced pluripotent stem cell cardiomyocytes (iPSC-CM). Based on the clinical data, iPSC-CM were chronically treated for 2 and 8 weeks with empagliflozin $(0.5 \mu \mathrm{mol} / \mathrm{l})$, and EC-coupling and electrophysiology were studied by blinded investigators.

\section{Methods}

\section{IPSC-CM and treatment}

All procedures were performed according to the Declaration of Helsinki and were approved by the local ethics committee. Informed consent was obtained from all tissue donors. IPSCs were cultured feeder-free and adherent by cultivating on Geltrex-coated cell culture dishes in the presence of chemically defined medium E8 (Life Technologies). Cardiac differentiation of iPSCs was performed by sequential targeting of the WNT pathway as described previously [13]. Briefly, undifferentiated iPSCs were cultured as a monolayer on Geltrex-coated 12-well dishes to a confluence of $85-95 \%$. Medium was changed to cardio differentiation medium composed of RPMI 1640 medium (Thermo Fisher Scientific) supplemented with $0.02 \%$ L-ascorbic acid 2-phosphate (Sigma Aldrich) and $0.05 \%$ albumin (Sigma Aldrich) including the GSK3 inhibitor CHIR99021 (4 $\mu \mathrm{mol} / \mathrm{L}$, Millipore) (d0). After $48 \mathrm{~h}$, medium was changed to fresh media supplemented with $5 \mu \mathrm{mol} / \mathrm{L}$ of the inhibitor of Wnt production-2 (IWP2, Millipore) for 2 days. From day 10 on, the cells were cultured in cardio culture medium (RPMI 1640 medium supplemented with $2 \mathrm{mmol} / \mathrm{L} \mathrm{l-glutamine}$ and 2\% B27 with insulin (Life Technologies)), with a medium change every $2-3$ days. CM were purified using metabolic selection for $2-4$ days by using $4 \mathrm{mmol} / \mathrm{L}$ lactate as carbon source after 20-40 days of differentiation [14] and studied on day 90 after initiation of differentiation except when mentioned otherwise. Following differentiation, purity of iPSC-CM was determined by flow analysis $\left(>90 \%\right.$ cardiac $\mathrm{TNT}^{+}$) or by morphology. Four- to 5-weekaged iPSC-CM were treated with $0.5 \mu \mathrm{mol} / \mathrm{l}$ empagliflozin for 2 or 8 consecutive weeks, which corresponds to the clinical relevant plasma concentration $[15,16]$. All investigators were blinded by an external independent instance during treatment, data acquisition, data analysis, and statistical testing. All analyses were performed in iPSC-CM with or without empagliflozin treatment. Four differentiation experiments of different iPSC lines from 3 healthy probands (female) were used.

\section{Epifluorescence microscopy $\left(\mathrm{Ca}^{2+}\right.$ transients and sarcoplasmic reticulum $\mathrm{Ca}^{2+}$ content)}

IPSC-CMs were loaded for 15 min with the ratiometric $\mathrm{Ca}^{2+}$ dye Fura- 2 AM $(5 \mu \mathrm{mol} / \mathrm{l})$. Solution was replaced by Tyrode's solution (in mmol/l: $\mathrm{KCl} 4, \mathrm{NaCl} 140, \mathrm{MgCl}_{2} 1$, HEPES 10, glucose $\left.10, \mathrm{CaCl}_{2} 1.25, \mathrm{pH} 7.4, \mathrm{NaOH}\right)$, and the respective agent (empagliflozin/vehicle control) and cells were left to incubate for another $15 \mathrm{~min}$ to ensure complete deesterification of intracellular Fura-2 and allow cellular rebalance of $\mathrm{Ca}^{2+}$ cycling properties. The Tyrode's solution was again replaced before measurements were started. Fura-2 fluorescence ratio was calculated using alternating excitation at $340 \mathrm{~nm}$ and $380 \mathrm{~nm}$. The emitted fluorescence was collected at $510 \mathrm{~nm}$. Measurements were performed with a fluorescence detection system (ION OPTIX Corp.). $\mathrm{Ca}^{2+}$ transients were recorded at steady-state conditions under constant field stimulation $(30 \mathrm{~V}, 10 \mathrm{~ms})$ during increasing frequencies $(0.25,0.5$, $1 \mathrm{~Hz}$ ) at room temperature. Sarcoplasmic $\mathrm{Ca}^{2+}$ content was assessed by caffeine application $(10 \mathrm{mmol} / \mathrm{L})$ after stopping field stimulation $(0.25 \mathrm{~Hz})$ to induce a complete sarcoplasmic 
reticulum $\mathrm{Ca}^{2+}$ release. The recorded $\mathrm{Ca}^{2+}$ transients were analyzed with the software IONWizard (ION OPTIX Corp.).

\section{Confocal microscopy (diastolic $\mathrm{Ca}^{2+}$ sparks)}

IPSC-CM were incubated with Fluo-4 AM $(10 \mu \mathrm{mol} / \mathrm{l})$ for $15 \mathrm{~min}$ before cells were incubated with Tyrode's solution for another $15 \mathrm{~min}$ as described above. $\mathrm{Ca}^{2+}$ spark measurements were performed with a laser scanning confocal microscope (LSM 7 Pascal, Zeiss) at room temperature. Fluo-4 was excited by an argon ion laser (488 nm), and emitted fluorescence was collected through a 505-nm long-pass emission filter. Fluorescence images were recorded in the line scan mode with 512 pixels per line (width of each scan line: $35.4 \mu \mathrm{m}$ ) and a pixel time of $0.64 \mu \mathrm{s}$. One image consists of 10,000 unidirectional line scans, equating to a measurement period of $\sim 6.9 \mathrm{~s}$. Experiments were conducted at resting conditions after loading the SR with $\mathrm{Ca}^{2+}$ by repetitive field stimulation for $10 \mathrm{~s}$ (at $0.5 \mathrm{~Hz}, 30 \mathrm{~V}, 5 \mathrm{~ms})$. Diastolic $\mathrm{Ca}^{2+}$ sparks were analyzed with the program SparkMaster for ImageJ. The $\mathrm{Ca}^{2+}$ spark frequency of each cell resulted from the number of sparks normalized to cell width and scan rate $\left(100 \mu \mathrm{m}^{-1} \mathrm{~s}^{-1}\right)$. The $\mathrm{Ca}^{2+}$ spark size was calculated as the product of spark amplitude, duration, and width. To compute the full $\mathrm{Ca}^{2+}$ leak per cell, $\mathrm{Ca}^{2+}$ spark size was multiplied with $\mathrm{Ca}^{2+}$ spark frequency [17].

\section{Action potential measurements}

IPSC-CM were incubated with Tyrode's solution and the respective agent (empagliflozin/vehicle control) for $15 \mathrm{~min}$ before measurements were started. For action potential recordings, whole-cell patch-clamp technique was used (current clamp configuration, HEKA electronics) [17, 18]. Microelectrodes (2-3 $\mathrm{M} \Omega$ ) were filled with (in $\mathrm{mmol} / \mathrm{L}$ ) $122 \mathrm{~K}$-aspartate, $8 \mathrm{KCl}, 10 \mathrm{NaCl}, 1 \mathrm{MgCl} 2,10 \mathrm{HEPES}$, and $5 \mathrm{Mg}$-ATP (pH 7.2, KOH). Action potentials were continuously elicited by square current pulses of $0.5-1 \mathrm{nA}$ amplitude and $1-5 \mathrm{~ms}$ duration at $0.25,0.5,1$, and $2 \mathrm{~Hz}$. Access resistance was $<15 \mathrm{M} \Omega$ after rupture. Fast capacitance was compensated in cell-attached configuration. Membrane capacitance and series resistance were compensated after patch rupture. Signals were filtered with 2.9 and $10 \mathrm{kHz}$ Bessel filters and recorded with an EPC10 amplifier (HEKA Elektronik) [19]. All experiments were conducted at room temperature.

\section{RNA sequencing (RNA-seq) and bioinformatics}

Differential gene expression was obtained by use of RNA sequencing performed on an Illumina HighSeq-4000 platform and bioinformatics. Total RNA was isolated from 3-monthold iPSC-CM from 2 controls with 2 differentiation each $(n=$ 4 samples) treated and non-treated with empagliflozin using standard protocols (Promega).
Quality and integrity of RNA were assessed with the Fragment Analyzer from Advanced Analytical by using the standard sensitivity RNA Analysis Kit (DNF-471). All samples selected for sequencing exhibited an RNA integrity number over 8 . RNA-seq libraries were performed using $150 \mathrm{ng}$ total RNA of a nonstranded RNA-seq, massively parallel mRNA sequencing approach from Illumina (TruSeq stranded total RNA Library Preparation, Illumina). Libraries were prepared on the automation (Beckman Coulter's Biomek FXP workstation). For accurate quantitation of cDNA libraries, a fluorometric based system, the QuantiFluor ${ }^{\mathrm{TM}} \mathrm{dsDNA}$ System from Promega, was used. The size of final cDNA libraries was determined by using the dsDNA 905 Reagent Kit (Fragment Analyzer from Advanced Bioanalytical) exhibiting a sizing of $300 \mathrm{bp}$ in average. Libraries were pooled and sequenced on the Illumina HiSeq 4000 (SE; $1 \times 50$ bp; 30-35 Mio reads/ sample).

Sequence images were transformed with Illumina software BaseCaller to BCL files, which was demultiplexed to fastq files with bcl2fastq v2.17.1.14.

Raw read and quality check Sequence images were transformed with Illumina software BaseCaller to BCL files, which was demultiplexed to fastq files with bcl2fastq v2.20.0.422. The sequencing quality was asserted using FastQC (Andrews, S. (2014). FastQC A Quality Control tool for High Throughput Sequence Data. http://www.bioinformatics. babraham.ac.uk/projects/fastqc/)(version 0.11.5).

Mapping and normalization Sequences were aligned to the reference genome Homo sapiens (hg38 version 96, https:// www.ensembl.org/Homo_sapiens/Info/Index) using the STAR aligner (Dobin, Alexander, et al. "STAR: ultrafast universal RNA- seq aligner." Bioinformatics 29.1 (2013): 15-21.) (version 2.5.2a) allowing for 2 mismatches within 50 bases. Subsequently, read counting was performed using featureCounts (Liao, Yang, Gordon K. Smyth, and Wei Shi. "featureCounts: an efficient general purpose program for assigning sequence reads to genomic features." Bioinformatics 30.7 (2013): 923-930.) (version 1.5.0-p1). Read counts were normalized in the R/Bioconductor environment (version 3.6.1, www.bioconductor.org) using the DESeq2 R package (Love, Michael I., Simon Anders, and Wolfgang Huber. "Moderated estimation of fold change and dispersion for RNA-seq data with DESeq2." Genome biology 15.12 (2014): 550.) version 1.24.0, where normalization was done by calculating the size factors for each sample and dividing by them.

\section{Western blots}

Pellets of iPSC-CMs were snap-frozen in liquid nitrogen and stored at $-80^{\circ} \mathrm{C}$. Protein lysates were prepared in cell lysis 
buffer containing (mmol/L) 20 Tris-HCl, $200 \mathrm{NaCl}, 20 \mathrm{NaF}, 1$ $\mathrm{Na}_{3} \mathrm{VO}_{4}, 1$ DTT, $1 \%$ Triton X-100 (pH 7.4), and complete protease and phosphatase inhibitor cocktails (Roche Diagnostics, Germany). About 20-25 $\mu \mathrm{g}$ of protein was loaded with SDS sample buffer $\left(30 \mathrm{~min}, 37^{\circ} \mathrm{C}\right.$ in $2 \%$ betamercaptoethanol). The protein samples were separated on $5 / 10 / 15 \%$ SDS-PAGE, transferred, and probed with the following primary antibodies: mouse monoclonal anti-GAPDH (1:30000, BTMC-A473-9, BIOTREND), rabbit polyclonal anti-RyR2 (1:15000, HPA020028, Sigma), mouse monoclonal anti-PLB (1:5000, MA3-922, Thermo Scientific), rabbit polyclonal anti-pCaMKII $(1: 1000$, PA5-36838, Thermo Scientific), rabbit polyclonal anti-CaMKII (1:5000, PA522168, Thermo Scientific), mouse monoclonal anti-NCX (1:1000, R3F1, Swant), and mouse monoclonal anti-SERCA (1:20000, MA3-919, Thermo Scientific). Secondary antibodies included HRP-conjugated goat anti-rabbit and goat antimouse (1:30000, 111-035-144 and 115-035-062, respectively, Jackson Immunoresearch). ImmobilonTM Western Chemiluminescent HRP Substrate (Millipore) was used for the chemiluminescent detection. The intensity of individual bands from Western blots was quantified using Image Studio Lite software, normalized to GAPDH, and then shown relative to the control group value.

\section{Statistics}

All data are presented as mean values \pm SEM. For statistical testing of longitudinal data including more than two groups, 2way ANOVA corrected for multiple comparisons by the
Sidak method was used. For comparison of two groups, Student's $t$ test was applied. Analysis was performed using GraphPad Prism 8. $P$ values were two-sided and considered statistically significant if $P<0.05$.

\section{Results}

\section{Effects of empagliflozin on systolic $\mathrm{Ca}^{2+}$ transients and SR $\mathrm{Ca}^{2+}$ load}

As empagliflozin was shown to (acutely) influence $\mathrm{Ca}^{2+}$ cycling $[9,10]$, we investigated the chronic effects $(2$ and 8 weeks) of empagliflozin on stimulated $\mathrm{Ca}^{2+}$ transients using epifluorescence microscopy (Fura-2). Caffeine application was used to assess the SR $\mathrm{Ca}^{2+}$ load. After 2 weeks of treatment, empagliflozin did not change systolic $\mathrm{Ca}^{2+}$ transient amplitude, diastolic $\mathrm{Ca}^{2+}$ levels, or the $\mathrm{Ca}^{2+}$ elimination kinetics during increasing stimulation frequencies $(0.25,0.5,1 \mathrm{~Hz})$ in iPSC-CM ( $n=127,116,91$ cells) compared with control $(n=124,116,88$ cells, Fig. $1 \mathrm{a}-\mathrm{b}$ and e-g). Moreover, SR $\mathrm{Ca}^{2+}$ load (caffeine-transient amplitude) was not altered in the empagliflozin group ( $n=14$ cells) compared with the control group ( $n=12$ cells, Fig. 1c-d and h). After 8 weeks of treatment, which corresponds to the time of onset of the clinical effects of empagliflozin, $\mathrm{Ca}^{2+}$ transient amplitude in control iPSC-CM (F340/380: $0.54 \pm 0.03, n=136$ cells) was not significantly different compared with the empagliflozin-treated group $(0.61 \pm 0.04, n=125$ cells $)$ at $0.25 \mathrm{~Hz}$ and during increasing frequencies up to $1 \mathrm{~Hz}$ (Fig. $2 \mathrm{a}-\mathrm{b}$ and e). Also,

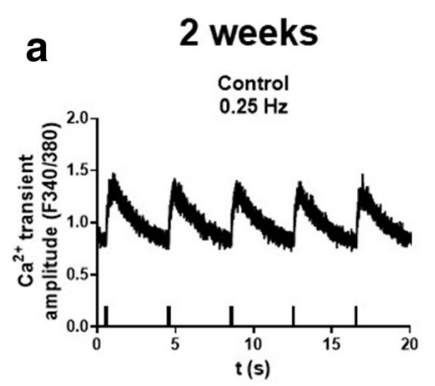

e

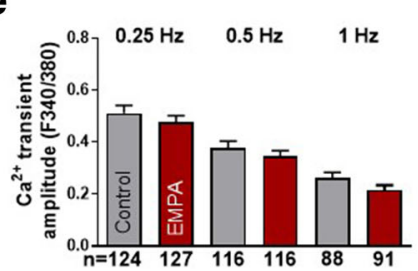

b

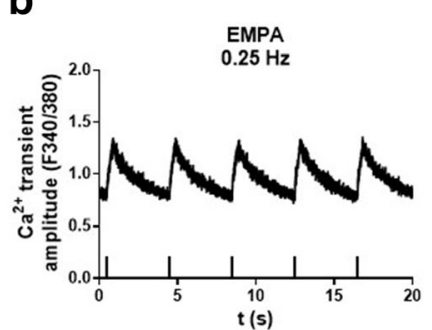

f

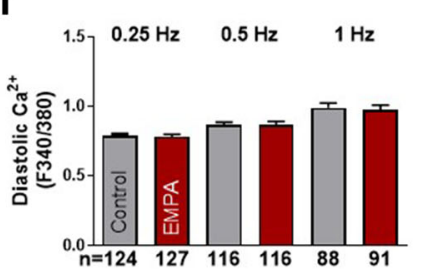

Fig. 1 Systolic $\mathrm{Ca}^{2+}$ transients and $\mathrm{SR} \mathrm{Ca}^{2+}$ load (epifluorescence microscopy, Fura-2 AM $5 \mu \mathrm{M}$ ) of human-induced pluripotent stem cell cardiomyocytes (iPSC-CM) after 2 weeks of treatment with either vehicle control (control) or $0.5 \mu \mathrm{mol} / 1$ empagliflozin (EMPA). (a-b) Original representative stimulated $\mathrm{Ca}^{2+}$-transient recordings at $0.25 \mathrm{~Hz}$ after 2 weeks of treatment and $(\mathbf{c}-\mathbf{d}) \mathrm{Ca}^{2+}$ transients recorded during application of $10 \mathrm{mM}$ caffeine indicating $\mathrm{SR} \mathrm{Ca}^{2+}$ load. (e) Mean data

C

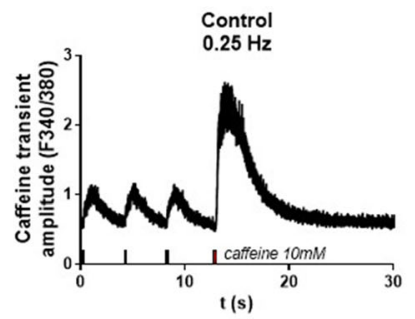

g

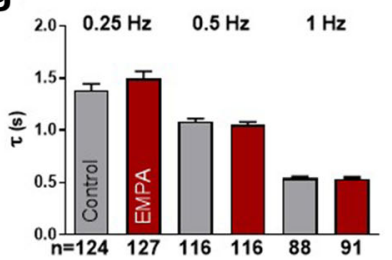

d

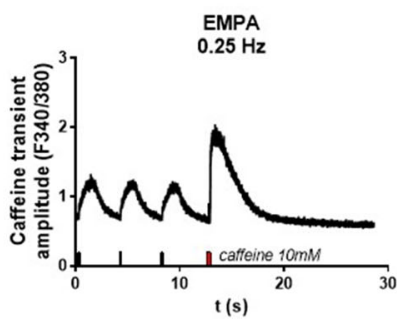

h

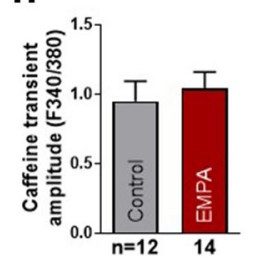

during increasing stimulation frequencies $(0.25,0.5$, and $1 \mathrm{~Hz})$ for systolic $\mathrm{Ca}^{2+}$-transient amplitude (f), diastolic $\mathrm{Ca}^{2+}$ levels, and (g) exponential decay time of $\mathrm{Ca}^{2+}$ transients $(\tau)$. (h) Mean data for caffeine-transient amplitude. The sample sizes of iPSC-CM are depicted below each column. Groups were statistically compared using two-way ANOVA with Sidak's test for multiple comparisons or Student's $t$ test (h) 


\section{8 weeks}

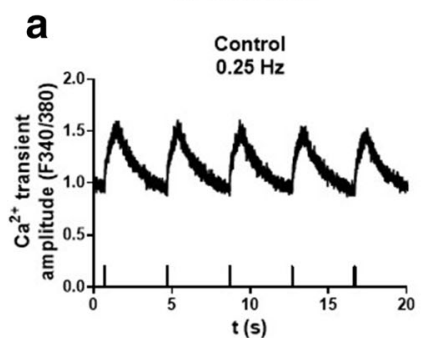

e

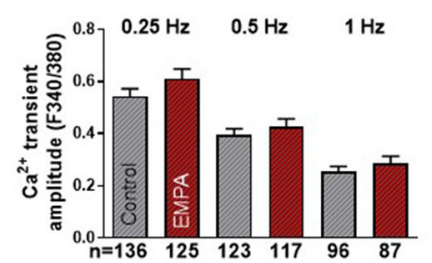

b

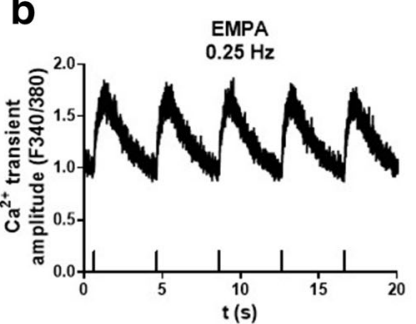

f

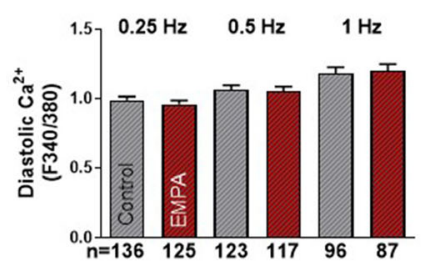

Fig. 2 Systolic $\mathrm{Ca}^{2+}$ transients and SR $\mathrm{Ca}^{2+}$ load (epifluorescence microscopy, Fura-2 AM $5 \mu \mathrm{M}$ ) of human-induced pluripotent stem cell cardiomyocytes (iPSC-CM) after 8 weeks of treatment with either vehicle control (control) or $0.5 \mu \mathrm{mol} / 1$ empagliflozin (EMPA). (a-b) Original representative stimulated $\mathrm{Ca}^{2+}$-transient recordings at $0.25 \mathrm{~Hz}$ of 8 weeks treated iPSC-CMs and (c-d) caffeine-induced transients indicating SR $\mathrm{Ca}^{2+}$ content. (e) Mean data during increasing stimulation

diastolic $\mathrm{Ca}^{2+}$ levels (F340/380 at $0.25 \mathrm{~Hz}$ : control: $0.99 \pm$ 0.02 , empagliflozin: $0.96 \pm 0.03$ ) and $\mathrm{Ca}^{2+}$ elimination (tau
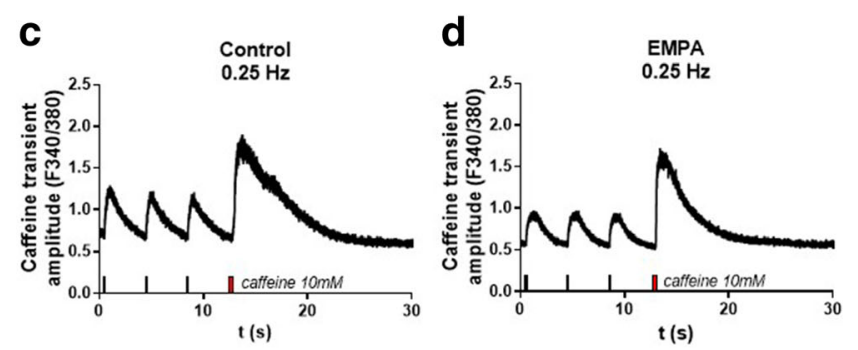

g

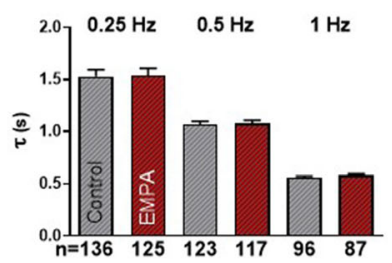

h

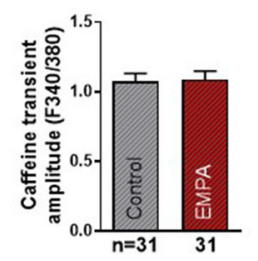

frequencies $(0.25,0.5$, and $1 \mathrm{~Hz})$ for systolic $\mathrm{Ca}^{2+}$-transient amplitude (f), diastolic $\mathrm{Ca}^{2+}$ levels, and (g) exponential decay time of $\mathrm{Ca}^{2+}$ transients $(\tau)$. (h) Mean data for caffeine-transient amplitude. The sample sizes of iPSC-CM are provided below the respective column. For statistical analysis, two-way ANOVA with Sidak's test for multiple comparisons or Student's $t$ test (h) was used

(s), $0.25 \mathrm{~Hz}$; control: $1.53 \pm 0.07 \mathrm{~s}$; empagliflozin: $1.54 \pm$ $0.07 \mathrm{~s}$ ) were not changed (Fig. $2 \mathrm{f}-\mathrm{g}$ ). In line with that, SR

a

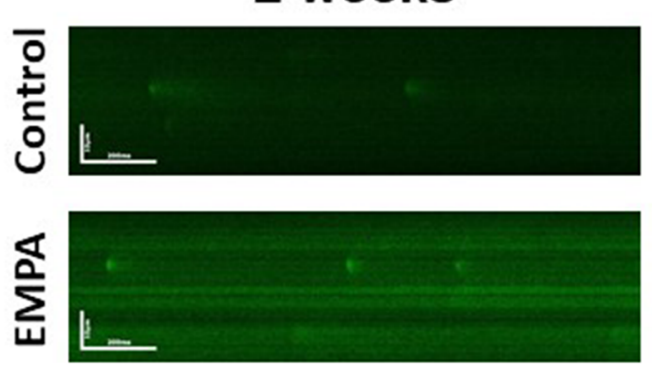

d

\section{8 weeks}

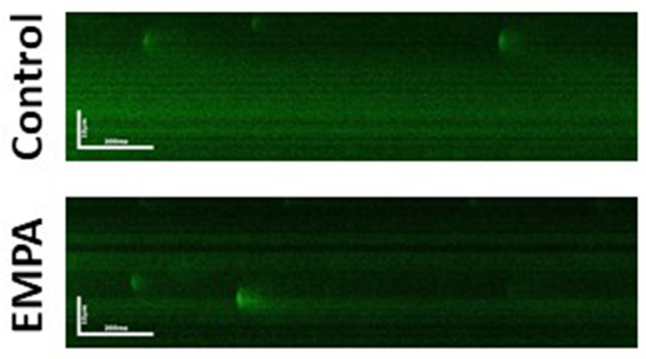

Fig. 3 Diastolic sarcoplasmic reticulum $\mathrm{Ca}^{2+}$ release (confocal microscopy, Fluo-4 AM $10 \mu \mathrm{M}$ ) of human-induced pluripotent stem cell cardiomyocytes (iPSC-CM) after 2 and 8 weeks of treatment with either vehicle control (control) or $0.5 \mu \mathrm{mol} / \mathrm{l}$ empagliflozin (EMPA). (a) Representative original confocal line scans showing diastolic $\mathrm{Ca}^{2+}$ sparks in iPSC-CM after 2 and (d) after 8 weeks treatment with empagliflozin b
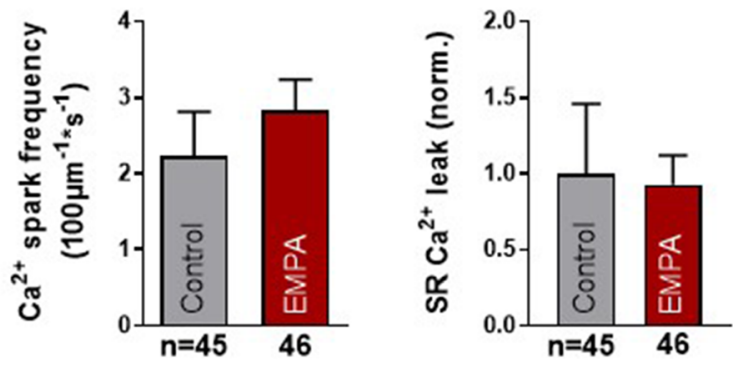

e
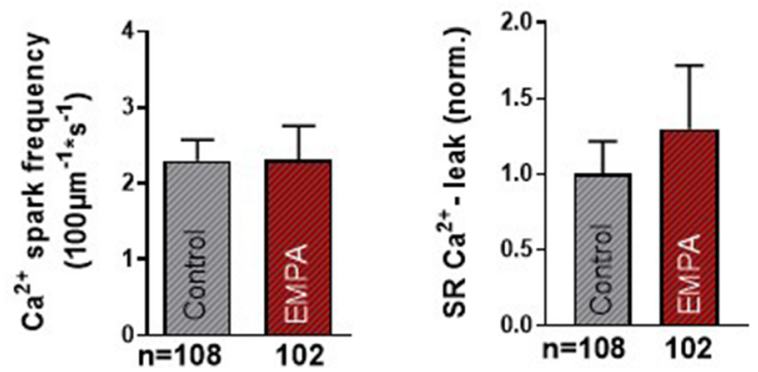

compared with vehicle control. (b) Mean data of diastolic $\mathrm{Ca}^{2+}$ spark frequency and (c) the total calculated diastolic $\mathrm{Ca}^{2+}$ leak (normalized to vehicle control) after 2 weeks and (e-f) 8 weeks of empagliflozin treatment. The sample sizes of iPSC-CM are presented below the respective column. Groups were statistically tested using Student's $t$ test 
$\mathrm{Ca}^{2+}$ load did not differ between control $(n=31$ cells) and empagliflozin $(n=31$ cells) after 8 weeks of treatment (Fig. $2 \mathrm{c}-\mathrm{d}$ and $\mathrm{h}$ ). Thus, chronic treatment with empagliflozin has neutral effects on cardiomyocyte systolic and diastolic $\mathrm{Ca}^{2+}$ cycling in iPSC-CM.

\section{Influence of chronic empagliflozin treatment on diastolic $\mathrm{Ca}^{2+}$ release in iPSC-CM}

Diastolic $\mathrm{Ca}^{2+}$ release via leaky RyR2 is a key mechanism for contractile dysfunction and arrhythmias in HF and other cardiac diseases [12]. Previous investigation suggested that empagliflozin reduces diastolic $\mathrm{Ca}^{2+}$ release in HF CM [9]. We therefore investigated the direct long-term effects of empagliflozin on diastolic SR $\mathrm{Ca}^{2+}$ release using confocal microscopy (Fluo-4). After 2 weeks of treatment with either empagliflozin $(n=46$ cells) or vehicle control $(n=45)$, empagliflozin showed no effects on diastolic $\mathrm{Ca}^{2+}$ spark frequency (Fig. 3a-b) and the total calculated diastolic $\mathrm{Ca}^{2+}$ leak (Fig. 3c) in iPSC-CM. After 8 weeks of treatment, which corresponds to the time where the clinical effects of empagliflozin became apparent, diastolic $\mathrm{Ca}^{2+}$ spark frequency in empagliflozin-treated iPSC-CM $(n=102$ cells) was determined at $2.3 \pm 0.4 / 100 \mu \mathrm{m} / \mathrm{s}$, but was not changed compared with iPSC-CM treated with vehicle control $(2.3 \pm 0.3$ /
$100 \mu \mathrm{m} / \mathrm{s}, n=108$, Fig. 3d-e). Accordingly, the total calculated diastolic $\mathrm{Ca}^{2+}$ leak did not differ in iPSC-CM treated with either empagliflozin or vehicle control (Fig. 3f).

\section{Effects of empagliflozin on cardiac action potentials}

The action potential is a critical component of cardiomyocyte electrophysiology and adverse electric remodeling in HF. To study potential direct effects of chronic empagliflozin treatment on the action potential, we investigated stimulated action potentials in iPSC-CM using the patch-clamp technique. In iPSC-CM treated for 2 weeks with empagliflozin $(n=53$ at $0.25 \mathrm{~Hz})$, we observed no differences in action potential duration at $80 \%$ repolarization (APD80), resting membrane potential, or action potential amplitude compared with control iPSC-CM $(n=50$, Fig. $4 \mathrm{a}-\mathrm{e})$. After 8 weeks of treatment, APD80 at $0.25 \mathrm{~Hz}$ was $344.4 \pm 15.4 \mathrm{~ms}$ in control-treated cells $(n=45)$. APD80 (358.5 $\pm 18.5 \mathrm{~ms})$ in empagliflozin-treated iPSC-CM $(n=43)$ was not significantly different compared to control (Fig. $4 \mathrm{f}-\mathrm{h}$ ). Also, resting membrane potential (control: $-62.4 \pm 1.0 \mathrm{mV}$; empagliflozin: $-64.3 \pm 1.1 \mathrm{mV}$ ) and action potential amplitude (control: $103.4 \pm 1.7 \mathrm{mV}$; empagliflozin: $104.4 \pm 1.8 \mathrm{mV}$ ) were not changed by empagliflozin after 8 weeks of treatment. In conclusion, empagliflozin showed neutral effects on cellular action potentials.

\section{2 weeks}

a

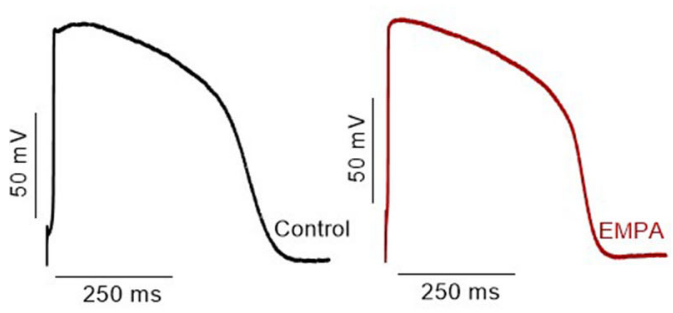

f

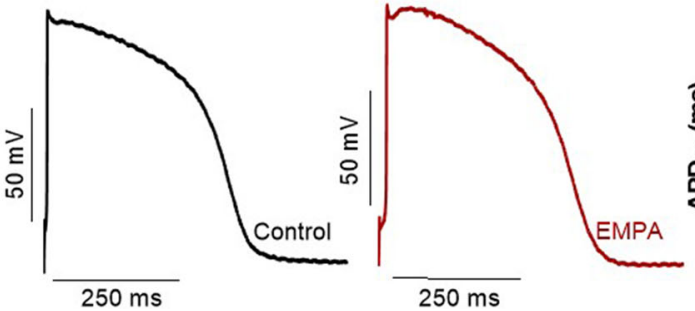

C

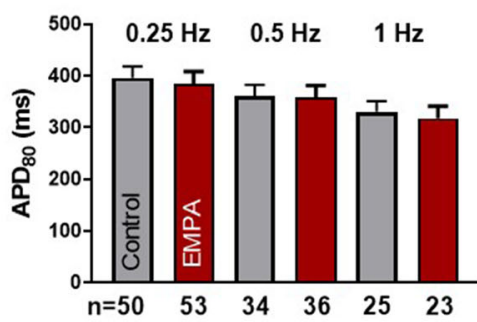

8 weeks

h

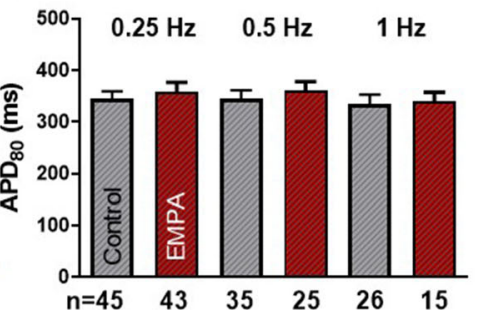

d
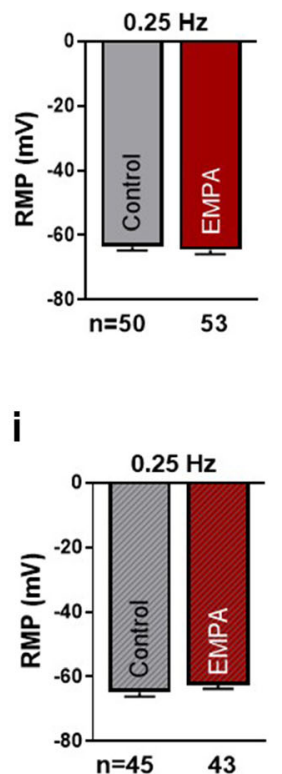

e

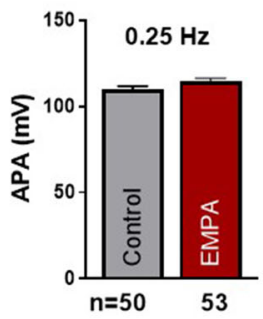

j

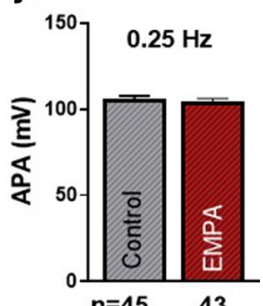

Fig. 4 Action potentials (patch-clamp technique) of human-induced pluripotent stem cell cardiomyocytes (iPSC-CM) after treatment with either vehicle control (Control) or $0.5 \mu \mathrm{mol} / 1$ empagliflozin (EMPA). (a) Representative action potential recordings $(0.25 \mathrm{~Hz})$ of human iPSC-CM treated for 2 weeks with vehicle control or (b) empagliflozin. (c) Effects of 2 weeks treatment with control or empagliflozin on action potential duration at $80 \%\left(\mathrm{APD}_{80}\right)$, (d) resting membrane potential (RMP) and (e) action potential amplitude (APA). (f) Original action potential recordings $(0.25 \mathrm{~Hz})$ of 8 weeks treated human iPSC-CM with either control or (g) empagliflozin. (h) Mean data for $\mathrm{APD}_{80}$, (i) RMP, and (j) APA of iPSC-CM after 8 weeks of treatment with control or empagliflozin. The sample sizes of iPSC-CM are provided below the respective column. For statistical testing, two-way ANOVA with Sidak's test for multiple comparisons (c and $\mathbf{h}$ ) or Student's $t$ test was used 


\section{Effects of chronic empagliflozin treatment on gene expression profiles of human iPSC-CM}

To further elucidate the molecular mechanisms underlying the pathogenesis of the empagliflozin-dependent phenotype, we performed RNA sequencing of iPSC-CM (4 differentiations from different cell lines from 2 donors), all with and without $0.5 \mu \mathrm{mol} / \mathrm{l}$ empagliflozin exposure for 8 weeks. After normalization for baseline expression, we did not identify differentially expressed genes (DEGs) between the untreated iPSC$\mathrm{CM}$ population and the iPSC-CM after empagliflozin treatment while focusing on important EC-coupling associated genes (Fig. 5a-d). Normalized counts of empagliflozintreated genes associated with systolic $\mathrm{Ca}^{2+}$ rise (RYR2), cytoplasmic $\mathrm{Ca}^{2+}$ extrusion (NCX, SERCA, PLN), cardiac remodeling (CAMKII), calcium binding (CALM1, CALM2, CASQ2), voltage-gated ion channels (SCN5A, CACNA1C, KCN5A), and $\mathrm{Ca}^{2+}$ transporting ATPase (ATP2B1) are shown in Fig. $5 \mathrm{a}-\mathrm{d}$.

\section{Protein expression of EC-coupling proteins}

To confirm our NGS findings on the protein level, we investigated the chronic effects of empagliflozin on regulatory EC-coupling proteins using Western blots analysis of treated iPSC-CM cultures (4 differentiations from different cell lines from 2 donors). Protein expression levels of EC-coupling proteins did not differ between 2 and 8 weeks. After 2 and 8 weeks of treatment, empagliflozin had no influence on protein expression of RyR2, which determines the systolic rise in $\left[\mathrm{Ca}^{2+}\right]_{\mathrm{i}}$ (Fig. 6a, b). Furthermore, SERCA2a, PLB, and NCX, regulating cytosolic $\mathrm{Ca}^{2+}$ extrusion, were not affected in iPSC-CM after chronic empagliflozin treatment for 2 or 8 weeks (Fig. 6c, d, g). Also, CaMKII, which directly regulates cardiomyocyte $\mathrm{Ca}^{2+}$ cycling and which is strongly associated with adverse cardiac remodeling, was in terms of expression and autophosphorylation not affected in iPSC-CM after chronic in vitro treatment for 2 or 8 weeks (Fig. 6e, f). a

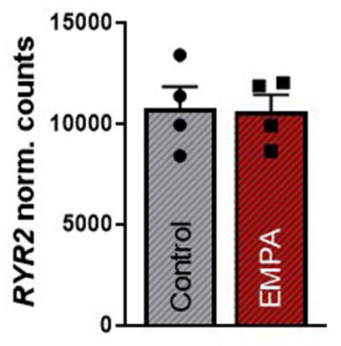

b

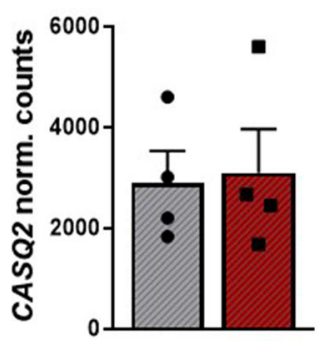

C

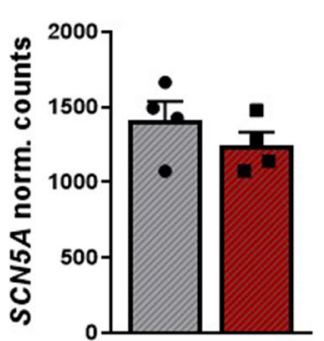

Fig. 5 Modulation of gene expression in human-induced pluripotent stem cell cardiomyocytes (iPSC-CM) after chronic ( 8 weeks) treatment with empagliflozin ( $0.5 \mu \mathrm{mol} / 1, n=4$ differentiations). (a) Empagliflozinaffected normalized counts of genes as ryanodine-receptor type 2 $(R Y R 2)$, sodium-calcium exchanger $(N C X 1)$, sarcoplasmic reticulum $\mathrm{Ca}^{2+}$ ATPase (SERCA), $\mathrm{Ca}^{2+}$-/calmodulin-dependent protein kinase II
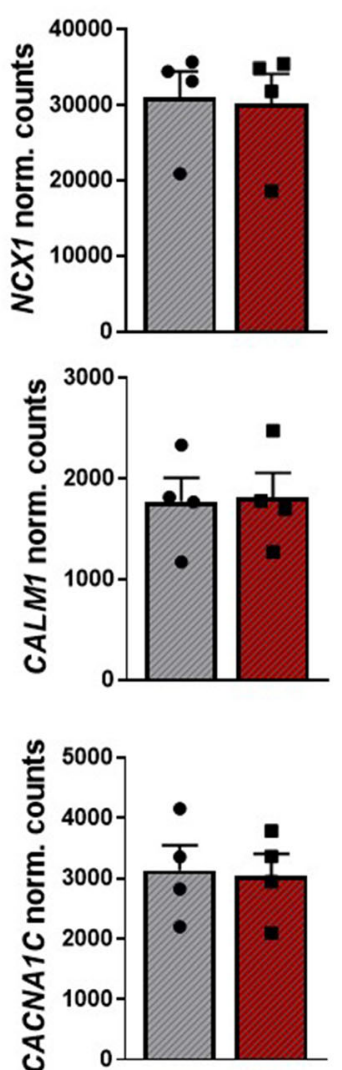

8 weeks
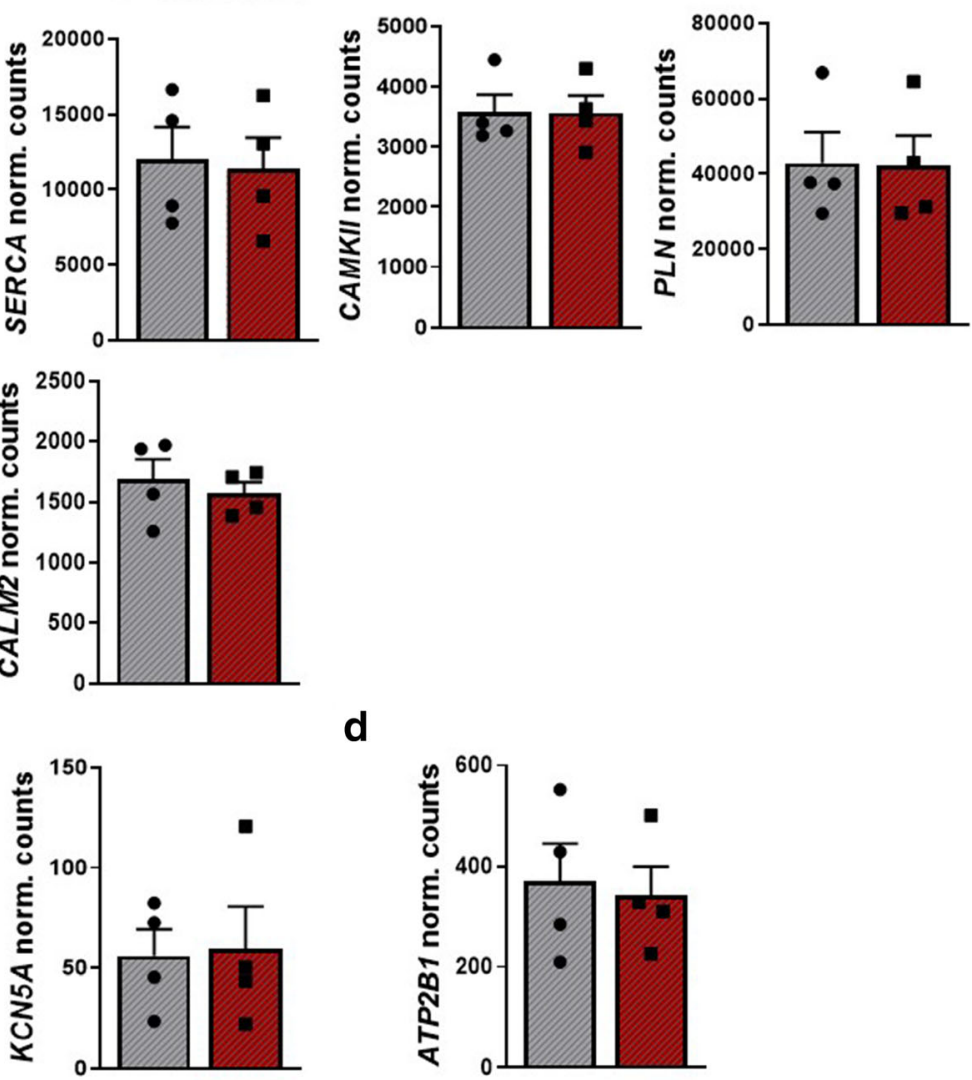

d

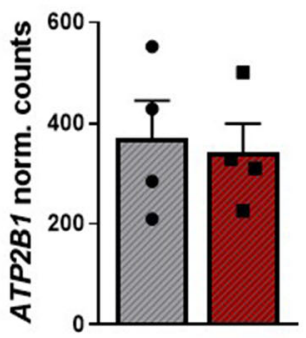

(CaMKII), phospholamban $(P L N)$, (b) calsequestrin 2 (CASQ2), calmodulin 1 (CALM1), calmodulin 2 (CALM2), (C) $\mathrm{Na}^{+}$voltage-gated channel alpha subunit $5(S C N 5 A), \mathrm{Ca}^{2+}$ voltage-gated channel subunit alpha1 $\mathrm{C}(C A C N A 1 C), \mathrm{K}^{+}$voltage-gated channel subfamily A member $5(K C N 5 A)$, (d) ATPase plasma membrane $\mathrm{Ca}^{2+}$ transporting 1 (ATP2B1). For statistical analysis, Student's $t$ test was applied 
a

2 weeks

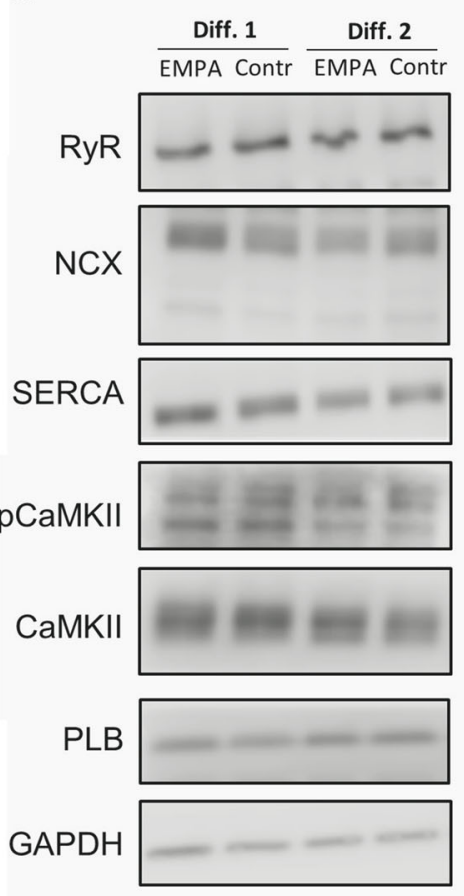

8 weeks

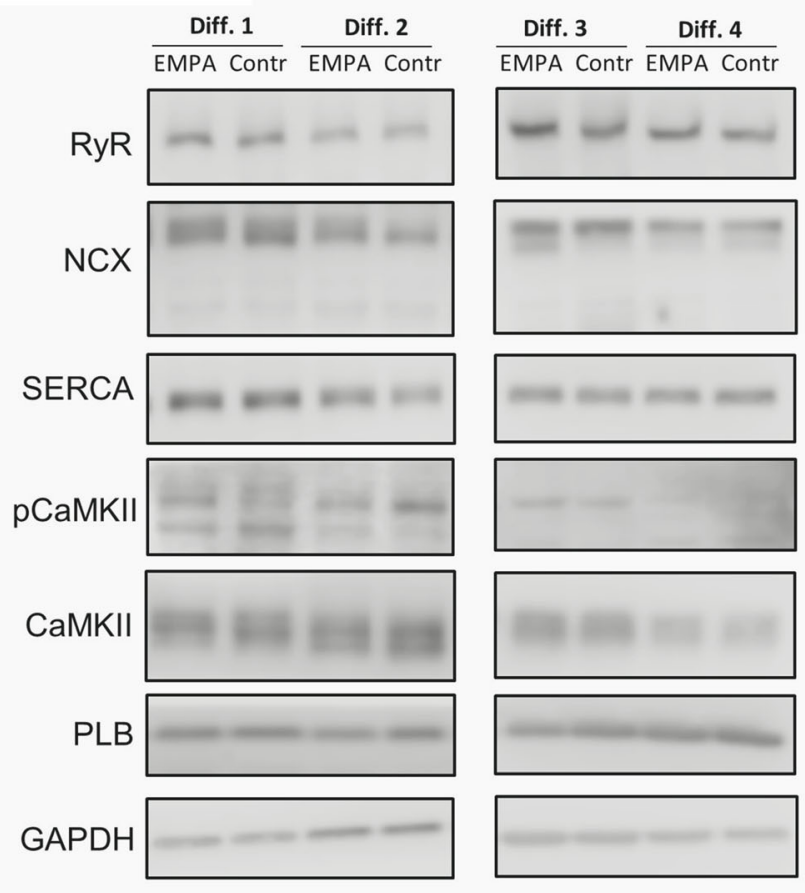

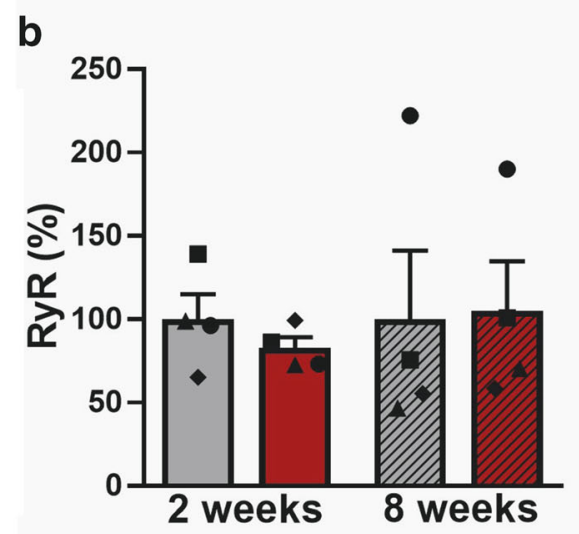
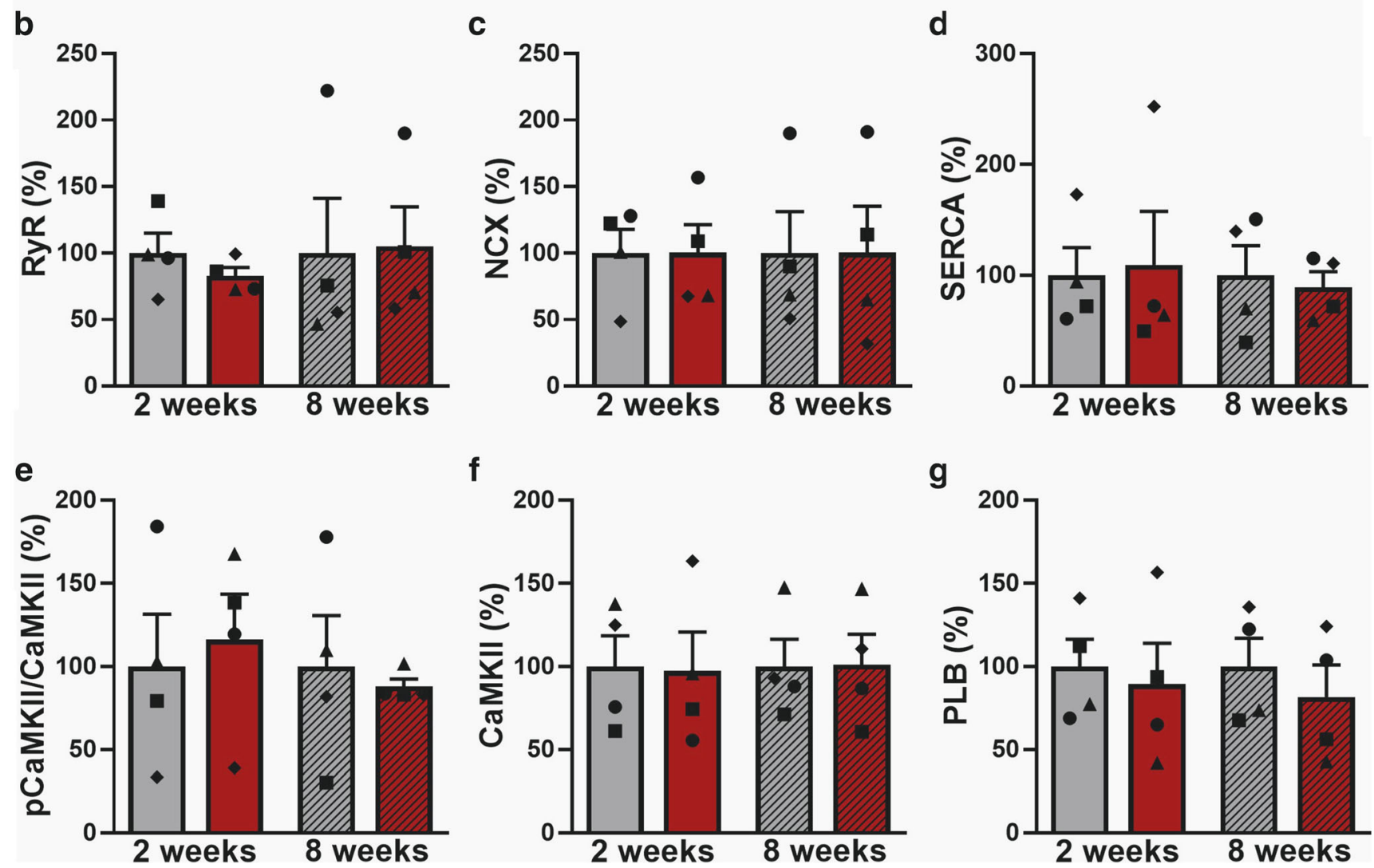

\section{Discussion}

This study investigated the direct long-term and thereby clinically relevant effects of empagliflozin on cardiomyocyte EC- coupling and electrophysiology in iPSC-CM. As different mechanisms of SGLT2 inhibitors have been proposed, we aimed to perform blinded treatment, data acquisition, and analysis with a high amount of experimental repetitions. 
Fig. 6 Western blot of EC-coupling proteins in human-induced pluripotent stem cell cardiomyocytes (iPSC-CM). (a) Representative original Western blots after treatment with empagliflozin (EMPA) or vehicle control (control) for 2 or 8 weeks from 4 differentiation experiments (Diff.) from 2 healthy donors. GAPDH was used as loading control. (b) Mean protein expression levels (normalized to the respective control group at 2 or 8 weeks) in iPSC-CM $(n=4$ differentiations, matched groups are displayed with matched individual symbols) and effects of 2 and 8 weeks treatment with empagliflozin (EMPA) on ryanodine-receptor type 2 (RyR2), (c) sodium-calcium exchanger (NCX), (d) sarcoplasmic reticulum $\mathrm{Ca}^{2+}$ ATPase (SERCA), (e) phosphorylated $\mathrm{Ca}^{2+}$-/calmodulin-dependent protein kinase II (pCaMKII), (f) $\mathrm{Ca}^{2+}$-/calmodulin-dependent protein kinase II (CaMKII), and (g) phospholamban (PLB). Groups were statistically analyzed using two-way ANOVA with Sidak's test for multiple comparisons

After 2 or 8 weeks of treatment, empagliflozin showed neutral effects on systolic $\mathrm{Ca}^{2+}$ transients and $\mathrm{SR} \mathrm{Ca}^{2+}$ content as well as diastolic $\mathrm{Ca}^{2+}$ release. Action potential properties were unchanged upon chronic empagliflozin treatment. Finally, mRNA and protein expression levels of key genes and proteins involved in EC-coupling were not changed by empagliflozin.

Mechanistic evidence is still lacking to fully understand the beneficial clinical effects of SGLT2 inhibitors on cardiovascular and HF outcomes. In particular, the effects of empagliflozin on EC-coupling, which is centrally involved in pathological cardiac remodeling and HF [12], are not fully understood. In order to enhance the translational relevance, this study therefore used human iPSC-CM as a human cardiomyocyte model since the translational potential of animal models is limited. Moreover, utilizing iPSC-CM facilitates large numbers of standardized individual measurements. Of note, we could demonstrate that human iPSC-CM represent a valid translational system for cardiomyocyte function and electrophysiology $[13,20]$. To investigate the direct cardiac effects of empagliflozin on cellular EC-coupling and to exclude systemic (secondary) effects on the myocardium (i.e., reduction in pre- and afterload), which could confound our observations, we directly treated iPSC-CM in vitro. Moreover, we performed a chronic treatment for up to 8 weeks in order to better mimic the situation of respective clinical trials, where the beneficial effects of empagliflozin became apparent after $\sim 2$ months of treatment [1]. Finally, iPSC$\mathrm{CM}$ treatment, data acquisition, and data analysis were performed by externally blinded investigators.

Our data demonstrated that in human iPSC-CM, empagliflozin had neutral effects on systolic $\mathrm{Ca}^{2+}$ transients and $\mathrm{SR} \mathrm{Ca}^{2+}$ content after 2 and 8 weeks of treatment. This result constitutes a safety signal as disturbed $\mathrm{Ca}^{2+}$ homeostasis can be associated with arrhythmias and negative inotropy. Moreover, long-term treatment with empagliflozin had neutral effects on action potential properties in human iPSC$\mathrm{CM}$, which is of relevance for cardiomyocyte electrophysiology as well as clinical safety. According to our findings on systolic $\mathrm{Ca}^{2+}$ transients, we previously did also not detect acute effects of empagliflozin on systolic $\mathrm{Ca}^{2+}$ transients in isolated CM from patients with HF [7]. However, data from animal cardiomyocyte studies showed an acute reduction of diastolic and systolic $\left[\mathrm{Ca}^{2+}\right]_{\mathrm{i}}[10]$, while other experimental animal data showed an increase in $\mathrm{Ca}^{2+}$ transient amplitude and $\mathrm{SR} \mathrm{Ca}^{2+}$ load upon exposure to empagliflozin [9]. Yet, adult CM from either animals or human are barely suitable for long-term treatment protocols, and methodological and species differences may limit the comparison of these studies. Nevertheless, while acute changes (up to $24 \mathrm{~h}$ ) in $\mathrm{Ca}^{2+}$ cycling might be suggested by the aforementioned studies [9, 10], we could here demonstrate that after a treatment duration according to the clinical trial situation, empagliflozin has neutral effects on systolic $\mathrm{Ca}^{2+}$ cycling. Of note, it should also be considered that most already established prognostic relevant drugs for treating HF have neutral or even negative effects on systolic $\mathrm{Ca}^{2+}$ cycling and inotropy [21]. According to our functional findings, mRNA and protein expression of RyR2 and CaMKII mediating systolic $\mathrm{Ca}^{2+}$ release were not affected by chronic empagliflozin treatment. Furthermore, NCX, SERCA, and PLB involved in cytosolic $\mathrm{Ca}^{2+}$ extrusion and (for SERCA and PLB) SR $\mathrm{Ca}^{2+}$ load were not altered in iPSC-CM after chronic empagliflozin treatment. Thus, these first data on the long-term effects of empagliflozin indicated that, at least in $\mathrm{CM}$, empagliflozin has neutral effects on EC-coupling gene as well as protein expression.

Furthermore, in human iPSC-CM, long-term treatment with empagliflozin did not affect diastolic $\mathrm{Ca}^{2+}$ release, which can contribute to cellular arrhythmogenesis and contractile dysfunction $[22,23]$. In line with that, RyR2 and CaMKII protein and mRNA expression as well as pCaMKII, which have been shown to strongly regulate diastolic $\mathrm{Ca}^{2+}$ sparks $[12,24]$, were not altered after chronic treatment with empagliflozin in iPSC-CM. However, previous data reported a reduction of diastolic $\mathrm{Ca}^{2+}$ sparks as well as CaMKII activity in both human and murine failing CM after 24-h treatment with empagliflozin [9]. In these cells, based on the HF phenotype (while our iPSC-CMs are healthy), a distinct cellular remodeling is present including altered CaMKII activity. Considering the duration of the treatment, acute regulatory stress/oxidative processes may underlie the acute CaMKIImediated reduction of $\mathrm{Ca}^{2+}$ sparks after exposure to empagliflozin in isolated human failing cells [9]. Nevertheless, we think that the treatment duration used in this study is according to the clinical trial situation, the more relevant approach to investigate the effects of empagliflozin.

In our study, we used iPSC-CM from healthy donors. Thus, the transfer of our results for particular cardiovascular diseases like diabetes or heart failure, where cardiac remodeling is present, might however be limited. 
As another recently proposed mechanism, inhibitory effects of SGLT2 inhibitors on NHE1 have been discussed [10]. Since NHE1 inhibition has less effects in healthy models [25] and its activity is less in healthy hearts [26], it would be possible that in a healthy model, empagliflozin could have effects on the NHE1 and subsarcolemmal $\mathrm{Na}^{+} / \mathrm{Ca}^{2+}$ homeostasis without greatly changing bulk $\left[\mathrm{Ca}^{2+}\right]_{i}$ in the SR or the cytoplasm. Therefore, in our study, we cannot rule out effects on NHE1 activity. Finally, also other beneficial direct cardiac mechanisms of empagliflozin, i.e., on myofilament function [7] and on inflammatory and oxidative (paracrine) signaling cascades, have been proposed $[8$, $27,28]$, which may serve as a rationale for further mechanistic studies.

In conclusion, we could demonstrate that after a clinically relevant treatment concentration and duration, empagliflozin has neutral effects on cardiomyocyte EC-coupling and electrophysiology in human iPSC-CM. Thus, at least in healthy cardiomyocytes, the beneficial clinical effects of empagliflozin seem to be not mediated by remodeling of cardiomyocyte EC-coupling, which has implications for further mechanistic investigation.

Acknowledgments We gratefully acknowledge the technical assistance of D. Riedl, J. Heine, S. Georgi-Beres, and Y. Metz.

Code availability Not applicable.

Authors' contributions S.P., F.R., N.D., O.S., G.S., K.H., and K.S.B. performed experiments and analyzed experimental data; S.P.,G.S., K.S.B., and S.S. interpreted the results of experiments; S.P., K.S.B., and S.S. performed the conception and design of research; J.M., G.H., N.H., L.S.M., K.S.B., and S.S edited and revised the manuscript; S.P. drafted the manuscript; S.S. and K.S.B. approved the final version of the manuscript.

Funding Open Access funding enabled and organized by Projekt DEAL. S. Pabel, K. Streckfuss-Bömeke, and S. Sossalla are funded by the ElseKröner-Fresenius Stiftung. S. Pabel is funded by the German Society of Internal Medicine. K. P. Hammer is funded by the DFG (HA 60107/3-1). L. Maier is funded by the DFG (MA 1982/5-1, 7-1).

Data availability The datasets generated during and/or analyzed during the current study are available from the corresponding author on reasonable request.

\section{Compliance with ethical standards}

Conflict of interest SS and LSM receive speaker's/consultancy honoraria from Boehringer Ingelheim Pharma GmbH. SP, FR, ND, OS, GS, $\mathrm{JM}, \mathrm{KH}, \mathrm{GH}, \mathrm{NH}$, and $\mathrm{KSB}$ have nothing to declare.

Ethics approval All procedures were performed according to the Declaration of Helsinki and were approved by the local ethics committee of the University Medical Center Göttingen.
Consent to participate Informed consent was obtained from all tissue donors.

Consent for publication The author transfers to Springer (respective to owner if other than Springer and for US government employees: to the extent transferable) the nonexclusive publication rights, and he/she warrants that his/her contribution is original and that he/she has full power to make this grant. The author signs for and accepts responsibility for releasing this material on behalf of any and all co-authors. This transfer of publication rights covers the nonexclusive right to reproduce and distribute the article, including reprints, translations, photographic reproductions, microform, electronic form (offline, online), or any other reproductions of similar nature.

Open Access This article is licensed under a Creative Commons Attribution 4.0 International License, which permits use, sharing, adaptation, distribution and reproduction in any medium or format, as long as you give appropriate credit to the original author(s) and the source, provide a link to the Creative Commons licence, and indicate if changes were made. The images or other third party material in this article are included in the article's Creative Commons licence, unless indicated otherwise in a credit line to the material. If material is not included in the article's Creative Commons licence and your intended use is not permitted by statutory regulation or exceeds the permitted use, you will need to obtain permission directly from the copyright holder. To view a copy of this licence, visit http://creativecommons.org/licenses/by/4.0/.

\section{References}

1. Zinman B, Wanner C, Lachin JM, Fitchett D, Bluhmki E, Hantel S, Mattheus M, Devins T, Johansen OE, Woerle HJ, Broedl UC, Inzucchi SE (2015) Empagliflozin, cardiovascular outcomes, and mortality in type 2 diabetes. N Engl J Med 373:2117-2128

2. Neal B, Perkovic V, Mahaffey KW, de Zeeuw D, Fulcher G, Erondu N, Shaw W, Law G, Desai M, Matthews DR (2017) Canagliflozin and cardiovascular and renal events in type 2 diabetes. N Engl J Med 377:644-657

3. Wiviott SD, Raz I, Bonaca MP, Mosenzon O, Kato ET, Cahn A, Silverman MG, Zelniker TA, Kuder JF, Murphy SA, Bhatt DL, Leiter LA, McGuire DK, Wilding JPH, Ruff CT, Gause-Nilsson IAM, Fredriksson M, Johansson PA, Langkilde AM, Sabatine MS (2019) Dapagliflozin and cardiovascular outcomes in type 2 diabetes. N Engl J Med 380:347-357

4. McMurray JJV, Solomon SD, Inzucchi SE, Kober L, Kosiborod MN, Martinez FA, Ponikowski P, Sabatine MS, Anand IS, Belohlavek J, Bohm M, Chiang CE, Chopra VK, de Boer RA, Desai AS, Diez M, Drozdz J, Dukat A, Ge J, Howlett JG, Katova T, Kitakaze M, Ljungman CEA, Merkely B, Nicolau JC, O'Meara E, Petrie MC, Vinh PN, Schou M, Tereshchenko S, Verma S, Held C, DeMets DL, Docherty KF, Jhund PS, Bengtsson O, Sjostrand M, Langkilde AM, Committees D-HT, Investigators (2019) Dapagliflozin in patients with heart failure and reduced ejection fraction. N Engl J Med 381:1995-2008 doi:

5. Fitchett D, Inzucchi SE, Cannon CP, McGuire DK, Scirica BM, Johansen OE, Sambevski S, Kaspers S, Pfarr E, George JT, Zinman B (2019) Empagliflozin reduced mortality and hospitalization for heart failure across the Spectrum of cardiovascular risk in the EMPA-REG OUTCOME trial. Circulation 139:1384-1395

6. Santos-Gallego CG, Requena-Ibanez JA, San Antonio R, Ishikawa K, Watanabe S, Picatoste B, Flores E, Garcia-Ropero A, Sanz J, Hajjar RJ, Fuster V, Badimon JJ (2019) Empagliflozin ameliorates 
adverse left ventricular remodeling in nondiabetic heart failure by enhancing myocardial energetics. J Am Coll Cardiol 73:1931-1944

7. Pabel S, Wagner S, Bollenberg H, Bengel P, Kovacs A, Schach C, Tirilomis P, Mustroph J, Renner A, Gummert J, Fischer T, Van Linthout S, Tschope C, Streckfuss-Bomeke K, Hasenfuss G, Maier LS, Hamdani N, Sossalla S (2018) Empagliflozin directly improves diastolic function in human heart failure. Eur J Heart Fail 20:1690-1700

8. Kolijn D, Pabel S, Tian Y, Lodi M, Herwig M, Carrizzo A, Zhazykbayeva S, Kovacs A, Fulop GA, Falcao-Pires I, Reusch PH, Van Linthout S, Papp Z, van Heerebeek L, Vecchione C, Maier LS, Ciccarelli M, Tschope C, Mugge A, Bagi Z, Sossalla S, Hamdani N (2020) Empagliflozin improves endothelial and cardiomyocyte function in human heart failure with preserved ejection fraction via reduced pro-inflammatory-oxidative pathways and protein kinase Galpha oxidation. Cardiovasc Res. https://doi.org/10. 1093/cvr/cvaa123

9. Mustroph J, Wagemann O, Lucht CM, Trum M, Hammer KP, Sag CM, Lebek S, Tarnowski D, Reinders J, Perbellini F, Terracciano C, Schmid C, Schopka S, Hilker M, Zausig Y, Pabel S, Sossalla ST, Schweda F, Maier LS, Wagner S (2018) Empagliflozin reduces Ca/ calmodulin-dependent kinase II activity in isolated ventricular cardiomyocytes. ESC Heart Fail 5:642-648

10. Baartscheer A, Schumacher CA, Wust RC, Fiolet JW, Stienen GJ, Coronel R, Zuurbier CJ (2017) Empagliflozin decreases myocardial cytoplasmic $\mathrm{Na}(+)$ through inhibition of the cardiac $\mathrm{Na}(+) / \mathrm{H}(+)$ exchanger in rats and rabbits. Diabetologia 60:568-573

11. Uthman L, Baartscheer A, Bleijlevens B, Schumacher CA, Fiolet JWT, Koeman A, Jancev M, Hollmann MW, Weber NC, Coronel R, Zuurbier CJ (2017) Class effects of SGLT2 inhibitors in mouse cardiomyocytes and hearts: inhibition of $\mathrm{Na}(+) / \mathrm{H}(+)$ exchanger, lowering of cytosolic $\mathrm{Na}(+)$ and vasodilation. Diabetologia 61: $722-726$

12. Fischer TH, Maier LS, Sossalla S (2013) The ryanodine receptor leak: how a tattered receptor plunges the failing heart into crisis. Heart Fail Rev 18:475-483

13. Borchert T, Hubscher D, Guessoum CI, Lam TD, Ghadri JR, Schellinger IN, Tiburcy M, Liaw NY, Li Y, Haas J, Sossalla S, Huber MA, Cyganek L, Jacobshagen C, Dressel R, Raaz U, Nikolaev VO, Guan K, Thiele H, Meder B, Wollnik B, Zimmermann WH, Luscher TF, Hasenfuss G, Templin C, Streckfuss-Bomeke K (2017) Catecholamine-dependent beta-adrenergic signaling in a pluripotent stem cell model of Takotsubo cardiomyopathy. J Am Coll Cardiol 70:975-991

14. Tohyama S, Hattori F, Sano M, Hishiki T, Nagahata Y, Matsuura T, Hashimoto H, Suzuki T, Yamashita H, Satoh Y, Egashira T, Seki T, Muraoka N, Yamakawa H, Ohgino Y, Tanaka T, Yoichi M, Yuasa S, Murata M, Suematsu M, Fukuda K (2013) Distinct metabolic flow enables large-scale purification of mouse and human pluripotent stem cell-derived cardiomyocytes. Cell Stem Cell 12:127-137

15. Heise T, Seewaldt-Becker E, Macha S, Hantel S, Pinnetti S, Seman L, Woerle HJ (2013) Safety, tolerability, pharmacokinetics and pharmacodynamics following 4 weeks' treatment with empagliflozin once daily in patients with type 2 diabetes. Diabetes Obes Metab 15:613-621

16. Scheen AJ (2014) Pharmacokinetic and pharmacodynamic profile of empagliflozin, a sodium glucose co-transporter 2 inhibitor. Clin Pharmacokinet 53:213-225

17. Pabel S, Mustroph J, Stehle T, Lebek S, Dybkova N, Keyser A, Rupprecht L, Wagner S, Neef S, Maier LS, Sossalla S (2020) Dantrolene reduces CaMKII $\delta$ C-mediated atrial arrhythmias. Europace 22:1111-1118
18. Pabel S, Ahmad S, Tirilomis P, Stehle T, Mustroph J, Knierim M, Dybkova N, Bengel P, Holzamer A, Hilker M, Streckfuss-Bomeke K, Hasenfuss G, Maier LS, Sossalla S (2020) Inhibition of NaV1.8 prevents atrial arrhythmogenesis in human and mice. Basic Res Cardiol 115:20 doi:https://doi.org/10.1007/s00395-020-0780-8

19. Sossalla S, Maurer U, Schotola H, Hartmann N, Didie M, Zimmermann WH, Jacobshagen C, Wagner S, Maier LS (2011) Diastolic dysfunction and arrhythmias caused by overexpression of CaMKIIdelta(C) can be reversed by inhibition of late $\mathrm{Na}(+)$ current. Basic Res Cardiol 106:263-272

20. Streckfuss-Bomeke K, Wolf F, Azizian A, Stauske M, Tiburcy M, Wagner S, Hubscher D, Dressel R, Chen S, Jende J, Wulf G, Lorenz V, Schon MP, Maier LS, Zimmermann WH, Hasenfuss G, Guan K (2013) Comparative study of human-induced pluripotent stem cells derived from bone marrow cells, hair keratinocytes, and skin fibroblasts. Eur Heart J 34:2618-2629

21. Ponikowski P, Voors AA, Anker SD, Bueno H, Cleland JGF, Coats AJS, Falk V, González-Juanatey JR, Harjola V-P, Jankowska EA, Jessup M, Linde C, Nihoyannopoulos P, Parissis JT, Pieske B, Riley JP, Rosano GMC, Ruilope LM, Ruschitzka F, Rutten FH, van der Meer P (2016) 2016 ESC guidelines for the diagnosis and treatment of acute and chronic heart failureThe task force for the diagnosis and treatment of acute and chronic heart failure of the European Society of Cardiology (ESC) developed with the special contribution of the heart failure association (HFA) of the ESC. Eur Heart J 37:2129-2200

22. Sossalla S, Fluschnik N, Schotola H, Ort KR, Neef S, Schulte T, Wittkopper K, Renner A, Schmitto JD, Gummert J, El-Armouche A, Hasenfuss G, Maier LS (2010) Inhibition of elevated Ca2+/calmodulin-dependent protein kinase II improves contractility in human failing myocardium. Circ Res 107:1150-1161

23. Hartmann N, Pabel S, Herting J, Schatter F, Renner A, Gummert J, Schotola H, Danner BC, Maier LS, Frey N, Hasenfuss G, Fischer TH, Sossalla S (2017) Antiarrhythmic effects of dantrolene in human diseased cardiomyocytes. Heart Rhythm 14:412-419

24. Fischer T, Herting J, Tirilomis T, Renner A, Neef S, Toischer K, Ellenberger D, Forster A, Schmitto J, Gummert J, Schondube F, Hasenfuss G, Maier L, Sossalla S (2013) CaMKII and PKA differentially regulate SR Ca2+-leak in human cardiac pathology. Circulation 128:970-981

25. Baartscheer A, Schumacher CA, van Borren MMGJ, Belterman CNW, Coronel R, Opthof T, Fiolet JWT (2005) Chronic inhibition of $\mathrm{Na}+\mathrm{H}+-$ exchanger attenuates cardiac hypertrophy and prevents cellular remodeling in heart failure. Cardiovasc Res 65:83-92

26. Yokoyama H, Gunasegaram S, Harding SE, Avkiran M (2000) Sarcolemmal $\mathrm{Na}+\mathrm{H}+$ exchanger activity and expression in human ventricular myocardium. J Am Coll Cardiol 36:534-540

27. Juni RP, Kuster DWD, Goebel M, Helmes M, Musters RJP, van der Velden J, Koolwijk P, Paulus WJ, van Hinsbergh VWM (2019) Cardiac microvascular endothelial enhancement of cardiomyocyte function is impaired by inflammation and restored by empagliflozin. JACC Basic Transl Sci 4:575-591

28. Zhazykbayeva S, Pabel S, Mügge A, Sossalla S, Hamdani N (2020) The molecular mechanisms associated with the physiological responses to inflammation and oxidative stress in cardiovascular diseases. Biophys Rev 12:947-968

Publisher's note Springer Nature remains neutral with regard to jurisdictional claims in published maps and institutional affiliations. 


\section{Affiliations}

\section{Steffen Pabel ${ }^{1} \cdot$ Florian Reetz $^{1} \cdot$ Nataliya Dybkova $^{2} \cdot$ Orr Shomroni $^{3} \cdot$ Gabriela Salinas $^{3}$ - Julian Mustroph ${ }^{1}$.} Karin P. Hammer ${ }^{1} \cdot$ Gerd Hasenfuss $^{2} \cdot$ Nazha Hamdani $^{4} \cdot$ Lars S. Maier $^{1} \cdot$ Katrin Streckfuss-Bömeke $^{2}$. Samuel Sossalla ${ }^{1,2}$ (i)

1 Department of Internal Medicine II, University Medical Center Regensburg, Franz-Josef-Strauß-Allee 11, 93053 Regensburg, Germany

2 Clinic for Cardiology \& Pneumology, Georg-August University Goettingen, and DZHK (German Center for Cardiovascular Research), Robert-Koch-Str. 40, 37075 Goettingen, Germany
3 NGS-Integrative Genomics (NIG) Institute Human Genetics (O.S., G.S.), University Medical Center Goettingen, Georg-August University, Goettingen, Germany

4 Institute of Physiology, Ruhr University Bochum, Bochum, Germany 